\title{
Training model for teaching endoscopic submucosal dissection of gastric tumors
}

\author{
E. Vázquez-Sequeiros, D. Boixeda de Miquel, J. R. Foruny Olcina, J. A. González Martín, M. García \\ D. Juzgado Lucas ${ }^{1}$, E. Garrido, C. González², A. Parra Blanco ${ }^{3}$, M. R. Arnau ${ }^{3}$, A. Buenadicha4, \\ V. Moreira Vicente, C. Martín de Argila and J. M. Milicua

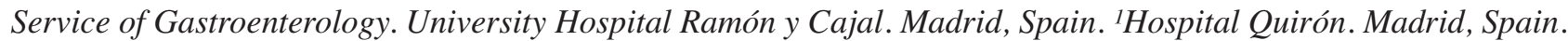 \\ Services of ${ }^{2}$ Pathology and ${ }^{4}$ General Surgery. University Hospital Ramón y Cajal. Madrid, Spain. ${ }^{3}$ Service of \\ Gastroenterology and Veterinary. Hospital Universitario. Santa Cruz de Tenerife, Spain
}

\begin{abstract}
Introduction: the elevated risk of complications and technical complexity of endoscopic submucosal dissection (ESD) has limited its implementation in our medical system.

Objective: to design and evaluate a training program for learning the ESD technique.

Methods: four endoscopists with no experience with ESD underwent a 4-step training program: 1) review of the existing literature, didactic material, and theoretical aspects of ESD; 2) ESD training in an ex-vivo animal model; 3) ESD training in an in-vivo animal model (supervised by ESD expert); and 4) ESD performance in a patient. A standard gastroscope and an ESD knife (IT, Flex or Hook-knife Olympus ${ }^{\circledR}$ ) were employed. The classical ESD technique was performed: rising of the lesion, circumferential incision, and submucosal dissection.

Results: ex-vivo animal model: $6 \mathrm{x}$ swine stomach/esophagus -cost < 100 euro; 6 x ESD: antrum $(n=2)$, body $(n=3)$ and fundus/cardia $(\mathrm{n}=1)-$; size of resected specimen: $4-10 \mathrm{~cm}$; ESD duration: 105-240 minutes; therapeutic success: $100 \%$; complications: perforation (1/6: 16\%) sealed with clips. In-vivo animal model: 6 ESD (antrum/body of stomach: 4; esophagus: 2); size: 2-5 cm; duration: 40-165 minutes; success: 100\%; complications: 0\%. Patient: ESD of a gastric lesion located in the antrum/body; size: $3 \mathrm{~cm}$; duration 210 minutes; a complete resection was achieved; no complications.
\end{abstract}

Conclusions: the results of the present study support the usefulness of this model for learning ESD in our system.

Key words: Endoscopic submucosal dissection. ESD. Submucosal resection. Large endoscopic resection.

\section{Received: 31-03-09.}

Accepted: 14-05-09.

Correspondence: Enrique Vázquez-Sequeiros. C/ Diego de Torres, 9-3 A. 28801 Alcalá de Henares. Madrid, Spain. e-mail: evazquezs@ hotmail.com
Vázquez-Sequeiros E, Boixeda de Miquel D, Foruny Olcina JR, González Martín JA, García M, Juzgado Lucas D, Garrido E, González C, Parra Blanco A. Arnau MR, Buenadicha A, Moreira Vicente V, Martín de Argila C, Milicia JM. Training model for teaching endoscopic submucosal dissection of gastric tumors. Rev Esp Enferm Dig 2009; 101: 546-552.

\section{INTRODUCTION}

Endoscopic mucosal resection (EMR) consists of resecting a superficial tumor of the gastrointestinal tract (esophagus, stomach, colon or rectum) by endoscopic means with curative intention (R0 resection) (1-5). An EMR-resected lesion may be submitted for pathological examination. One of the advantages of EMR compared with surgical resection is its lower morbidity/mortality and cost. At present EMR has become widely available in clinical practice in both Asian and Western countries (15). However, EMR presents a number of limitations: a) technical difficulty; b) risk for complications: bleeding (2-29\%), perforation $(0.36 \%)$ and stenosis (mainly in the esophagus); and c) restricted to superficial lesions with no lymphatic spread and size $<1-1.5 \mathrm{~cm}(1-8)$. Lesions with a diameter $>1.5 \mathrm{~cm}$ cannot be completely resected with a single EMR procedure, and repeated mucosectomies (several fragments) or endoscopic submucosal dissection (ESD) (allowing to resect the entire lesion in a single piece) will be required (2). It is generally assumed that it is better to resect tumoral lesions in single pieces, as we can be sure the tumor has been completely resected, and it also facilitates sample orientation at the time of the pathology study (8-15). Furthermore, ESD allows to perfom wider and deeper resections versus EMR (2). However, the learning curve for ESD (high technical difficulty) is longer (compared with EMR), and complication rates are also superior ( $30 \%$ of perforations in some studies) even in expert hands (8-15). These factors have 
somehow limited, in contrast to Asian countries (with a high incidence of superficial tumors that may be potentially treated by ESD), the availability of ESD in Western countries (low incidence of superficial lesions). This statement is supported by the fact that there is to date no original report on ESD in our country. On the other hand, the absence of experts on ESD in our country, and the lack of validated models for training endoscopists in this technique, may contribute to this situation.

For this reason, we conducted a prospective, controlled study with the following aim: to identify a safe, effective, easily reproducible, and inexpensive model for learning ESD in our country.

\section{MATERIAL AND METHODS}

Four therapeutic endoscopists (EVS, DBM, JAGM, JRFO) with no prior exposure to NOTES participated in this study. These endoscopists underwent a 4-step training program on ESD:

- Step 1: Review of the literature for theorectical concepts on ESD: a careful search of the literature on ESD was performed (using Pubmed as a reference and keywords like "endoscopic mucosal resection", "ESD", "submucosal resection", and "large endoscopic resection"). Original manuscripts and reviews on this subject were identified, provided to the endoscopists participating in the study (review of the literature, learning of material, theoretical aspects on ESD), and finally a PowerPoint presentation with videos showing the different phases of the ESD technique was performed.

- Step 2: Training in an ex-vivo animal (swine) model (esophagus-stomach): a search for alternative models to facilitate the learning of ESD disclosed that humans and swines have a similar anatomy and histology. The size of the esophagus and stomach of a $25-30-\mathrm{kg}$ pig is large enough to allow the use of standard endoscopes and ESD tools as required for this learning project.

To create this ex-vivo animal model, a total of 6 stomachs and esophaguses of pigs were used. Stomachs employed in the experiment were used within 48-72 hours after animal slaughter in an attempt to preserve the elastic properties of the wall. Stomachs and esophaguses were kept in a refrigerator at a temperature above $0^{\circ}$ Celsius. Ex-vivo specimens were retrieved from the refrigerator 3-4 hours before the experiment for warming. Figure 1A shows an example of the model created for this study. The endoscope was introduced through a plastic overtube until the gastric cavity was reached, and inflated with the endoscope. A target area for ESD was selected in the stomach, resection margins were marked with argon plasma, and ESD was performed in this segment as described below in this manuscript $(2,10,16)$. Once ESD had been completed, the resection specimen was retrieved and the integrity of the stomach wall was investigated by filling the gastric cavity with 1-2 liters of water (search for leaks) (Fig. 1B). The 4 participating endoscopists performed a total of 6 experiments in this ex-vivo model.

-Step 3: Training in an in-vivo animal/swine model: after phase 2 (initial training and learning to use ESD specific tools) two of these endoscopists attended an ESD training course in a live swine model $(25-30 \mathrm{~kg})$ given by an endoscopist experienced in ESD (> 300 resections) (Dr. Y. Saito). This course was held at the "Hospital Universitario de Tenerife" in January 2008 under the direction of one of the co-authors of this study (Dr. Adolfo Parra) and the supervision of Dr. Y. Saito. Animals un-

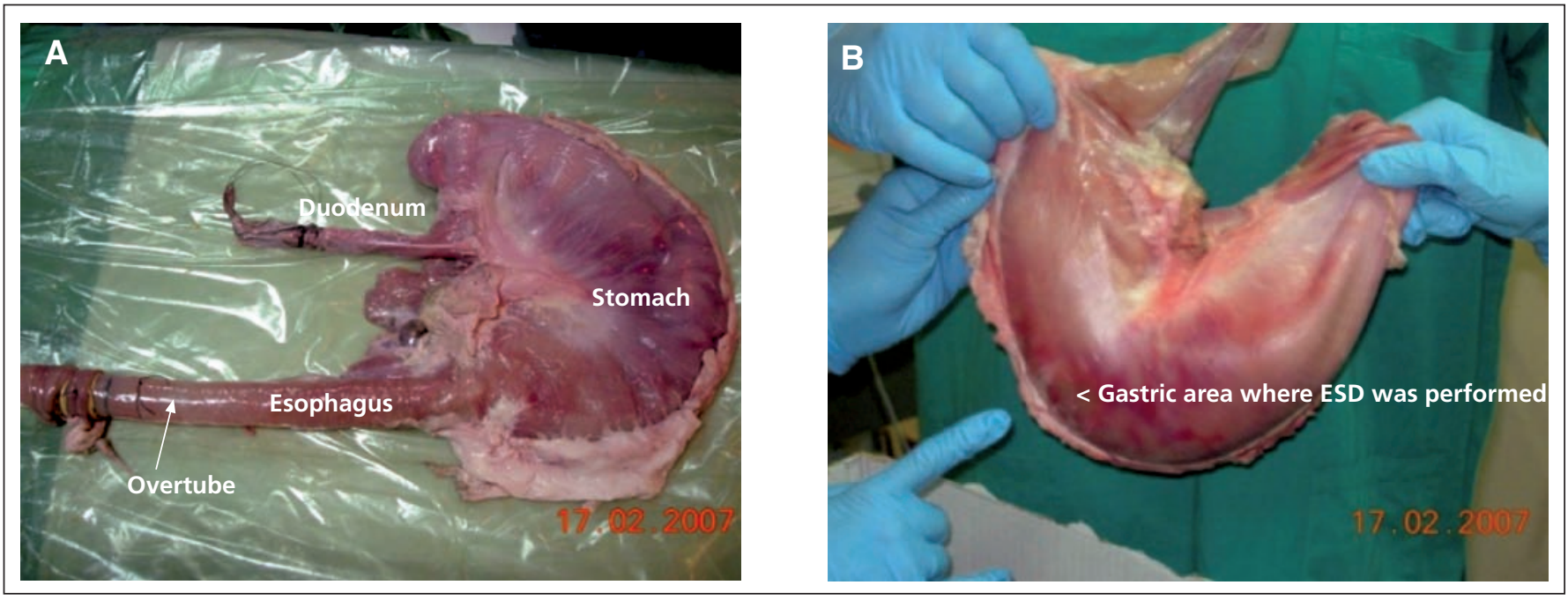

Fig. 1. A. The model for ESD consisted of 8-10 cm of the esophagus, the stomach and the duodenum. All structures were intact. The duodenum was sutured and an 18-mm-diameter overtube was introduced in the esophageal lumen to the gastric cavity. Suture closing of the esophagus and the overtube was performed with surgical sutures and elastic rubber bands. B. At the end of the ESD procedure the area of resection was assessed for leaks secondary to inadverted perforations. 
derwent sedation with $10 \mathrm{mg} / \mathrm{kg}$ i.m. ketamine and 20 $\mathrm{mg} / \mathrm{kg}$ of sodium thiopentate, then underwent intubation and maintained under general anesthesia by the use of sevofluorane $2-2.5 \%$ in $100 \% \mathrm{O}_{2}$. Drugs for muscle relaxation (vencuronium bromide) and analgesia (fentanyl) were administered as needed during the procedure. A conventional endoscope was introduced through the port until the gastric cavity was reached, and ESD was performed. The expert in ESD was present during the procedure and gave the endoscopist advise about the best strategy for resection -a) use of one type of ESD knife or another; b) need to elevate the lesion: amount of solution, location, strategy of elevation to facilitate ESD; and c) ESD performed via a forward or a retoflexed view. If any complication arose during the procedure, the expert helped the novice to identify and treat it as soon as possible. A total of 6 experiments were performed in this live animal model (results presented in the results section of this manuscript).

-Step 4: ESD of a gastric tumor in a patient: after completing a basic training (theory and practice in an $e x$ vivo and an in-vivo model) on ESD, a patient who might benefit from this type of therapy was identified. This case was presented in images to the ESD expert, who agreed with the authors about the convenience of ESD therapy for the lesion identified. To perform ESD in this patient, the Surgical Laparoscopy Unit of the Hospital was contacted and the ESD procedure was performed under general anesthesia in the OR room, with the surgical team available to solve any complication not amenable for endoscopic treatment that might occur during ESD.

\section{Technique for ESD employed in the present study}

After a careful search for the different ESD techniques available in the literature, the following technique was adopted for the present study $(2,10,16)$. A standard gastroscope (Olympus ${ }^{\circledast}$ EVIS EXERA II video gastroscope GIF-Q165: diameter $9.2 \mathrm{~mm} /$ therapeutic channel of 2.8 $\mathrm{mm})$, translucent EMR cap Olympus ${ }^{\circledast}$ at the distal end of the endoscope to facilitate ESD, needle knife (Boston Scientific ${ }^{\circledast}$, Natick, Mass), electric ESD knife (IT-knife, Flex-knife and Hook-knife Olympus ${ }^{\circledR}$ ), and an Erbe electric generator were employed. As required by the law, experiments performed in the porcine model (ex-vivo and in-vivo) were carried out with endoscopes dedicated to animal use. The target area for resection was selected -a) theoretical area for ESD in the animal model; and b) tumor area in the patient- by circumferentially marking the margins of the lesion at $5 \mathrm{~mm}$ intervals with argon plasma $(50 \mathrm{~W})($ Fig. 2A). The area for resection was then elevated (saline serum $13 \mathrm{cc}+$ adrenaline $1 \mathrm{cc} / \mathrm{mg}+$ indigo carmin $2 \mathrm{cc}+20 \%$ glycerol $4 \mathrm{cc}$ ) and a $1^{\text {st }}$ incision was performed until the submucosal layer was reached (Fig. 2B) (needle knife) and a full $360^{\circ}$ circumferential incision around the lesion was performed (combined use of
ITknife Olympus ${ }^{\circledR}$ and Hook-knife Olympus ${ }^{\circledR}$ ) (Table I) (Fig. 2C). An incision was performed at the 6,2 and 12 hours of the lesion in order to facilitate its circumferential resection. Finally, a complete dissection of the submucosal layer was performed with the assistance of a transparent EMR cap and an ESD electric knife (ITknife Olympus $^{\circledast}$ or Hook-knife Olympus ${ }^{\circledR}$ ), following the typical strategy for dissection (starting from the distal margin and continuing with the proximal margin of the lesion) and positioning the endoscope in a retroflexed and frontal view position. The area of resection was elevated as many times as needed during ESD. In cases where a vessel was visualized during ESD, a coagulation forceps was used to coagulate (parameters presented in Table I). In case of a small perforation or bleeding during ESD, hemostatic clips were placed (Resolution Clip. Boston Scientifics $^{\circledR}$ ) for treatment.

An Ethics Committee approval was obtained to conduct this study in an animal model for learning ESD.

\section{RESULTS}

\section{Step 1: Review of literature for theoretical concepts on ESD}

A search was made based on criteria previously described, and a total of 257 articles (34 reviews) on ESD were identified. An in-depth analysis of the existing reviews on ESD, and of articles detailing the ESD technique was conducted. ESD videos available at the DAVE Project's web page (http://daveproject.org/) and Gastrointestinal Endoscopy published articles containing ESD videos (http://journals.elsevierhealth.com/periodicals/ymge) were reviewed. A DVD edited by the American Society for Gastrointestinal Endoscopy (ASGE) in 2007 explaining the ESD technique was also reviewed.

\section{Step 2: ESD in an ex-vivo model}

A total of 6 ESDs of "target lesions" on a healthy mucosa (antrum: $\mathrm{n}=2$; body: $\mathrm{n}=3$; fundus/subcardial: $\mathrm{n}=$ 1) were performed by following the technique described. All target lesions (except the one located in the fundus/subcardial area) were located in the anterior or posterior wall of the stomach. Resection specimens ranged from 4 to $10 \mathrm{~cm}$ in length (median: $6 \mathrm{~cm}$ ). ESD duration ranged from 105 to 240 minutes (median: 175 minutes). ESD could be completed in all cases (technical success: $6 / 6=100 \%$ ). A $2-\mathrm{mm}$ perforation occurred while performing ESD with the Hook-knife of a fundus/subcardial lesion $(1 / 6=17 \%)$. This perforation could be sealed by placing 2 endoscopic clips, and ESD could be completed afterwards. A post-ESD examination of the stomach showed no sign of perforation/leak (including the stomach with the $2 \mathrm{~mm}$ perforation sealed 

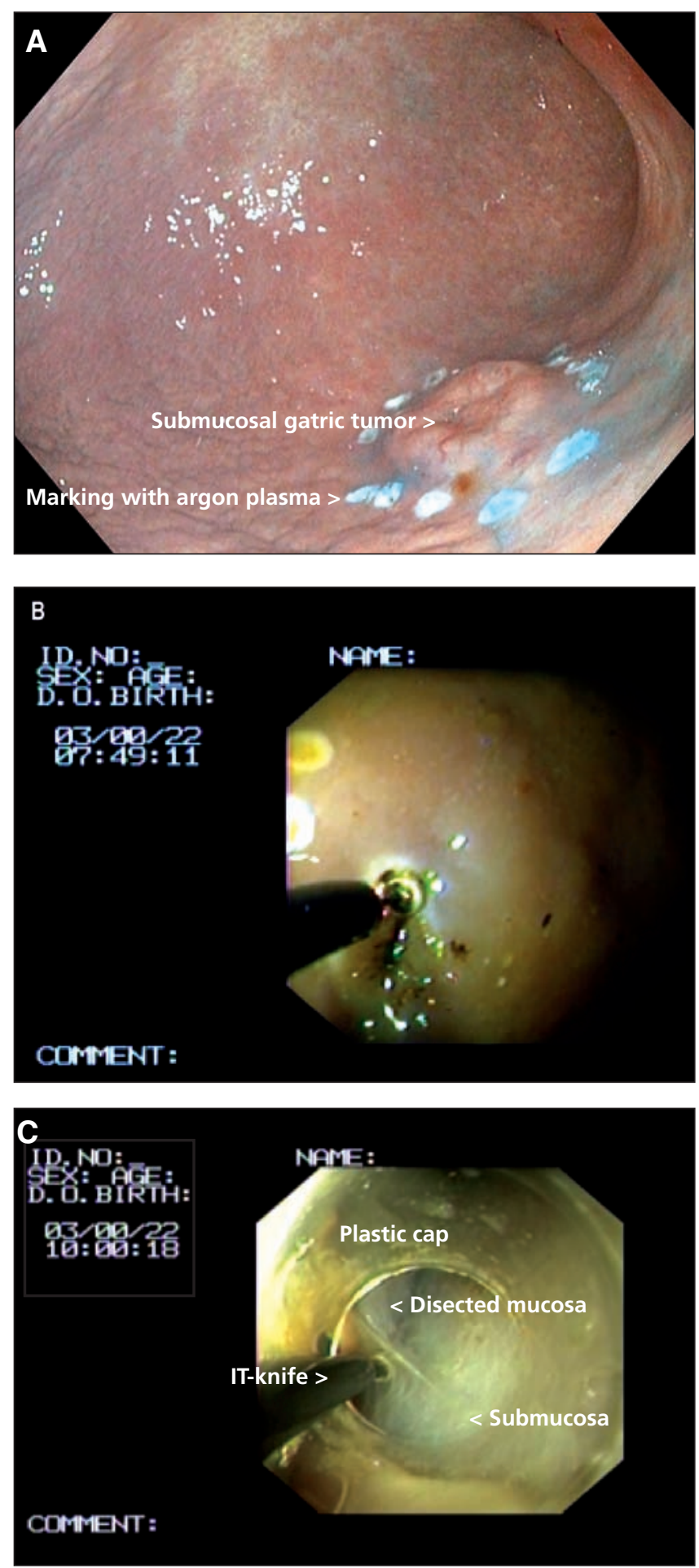

Fig. 2. A. Resection margins were marked with argon plasma in order to facilitate recognition of the area for resection, and to ensure complete resection. $\mathrm{B}$. The target lesion was raised (initial elevation of borders and posteriorly of the central zone) by injecting the solution described in the methods section, and then a $2-3 \mathrm{~mm}$ incision into the submucosa was done. At this time a circumferential incision of the entire margin of the lesion was performed. C. Finally, an endoscopic submucosal dissection was conducted with the help of an ESD electric knife (IT-knife), until a complete resection of the lesion was accomplished.
Table I. Endoscopic submucosal dissection: parameters used

a. Dissection: (cut)

a.1. IT KNIFE:

- ENDOCUT 80-120W EFFECT 3

\section{a.2. FLEX KNIFE. \\ - 40-60W. FORCED}

b. Coagulation: (coag)

- Vessels 1 mm: IT Knife: FORCED COAG 40-60W

- Vessels 2-3 mm: Coagulation forceps: SOFT COAG 80W

with clips). The estimated cost of this ex-vivo animal model was $<100$ euros ( 6 pig stomachs), and allowed all 4 endoscopists/researchers participating in the study to have a first approach to ESD, identify problems and difficulties associated with this technique, and finally reach certain technical skills to perform ESD.

\section{Step 3: ESD in the in-vivo animal model}

ESD was performed in a live porcine model under general anesthesia, orotracheal intubation and mechanical ventilation. A total of 6 ESDs of "target lesions" located on the anterior and posterior wall of the antrum/body $(n=4)$ and distal esophagus $(n=2)$ were completed under the supervision of an expert on ESD. The size of "target lesions" ranged from 2 to $5 \mathrm{~cm}$ (median: $3 \mathrm{~cm}$ ). The duration of the ESD procedure ranged from 40 to 165 minutes (median: 125 minutes). All ESD procedures could be completed (technical success: $6 / 6=$ $100 \%)$. No significant complications were registered $(0 / 6$ $=0 \%$ ). Animals were sacrificed at the end of the exam, and therefore long term complications could not be investigated.

\section{Step 4: ESD in a patient}

A candidate for ESD was identified and presented (Power Point and videos) to the ESD expert to elucidate the adequacy of the candidate and to decide the best diagnostictherapeutic strategy to successfully complete the ESD. The patient presented with a 2-year history of chronic active gastritis and was Helicobacter pylori-positive (had successfully underwent eradication therapy). The lesion was flat, borders were slightly elevated, and the mucosa appeared to be normal on endoscopy (Fig. 3A); repeated biopsies were diagnostic of chronic active gastritis, intestinal metaplasia and moderate dysplasia in some of the samples. Endoscopic ultrasounds: 4 × $20 \mathrm{~mm}$, flat, hypoechogenic lesion, affecting the deep mucosa and submucosa. Due to the uncertain diagnosis despite repeated biopsies, an ESD of the lesion 

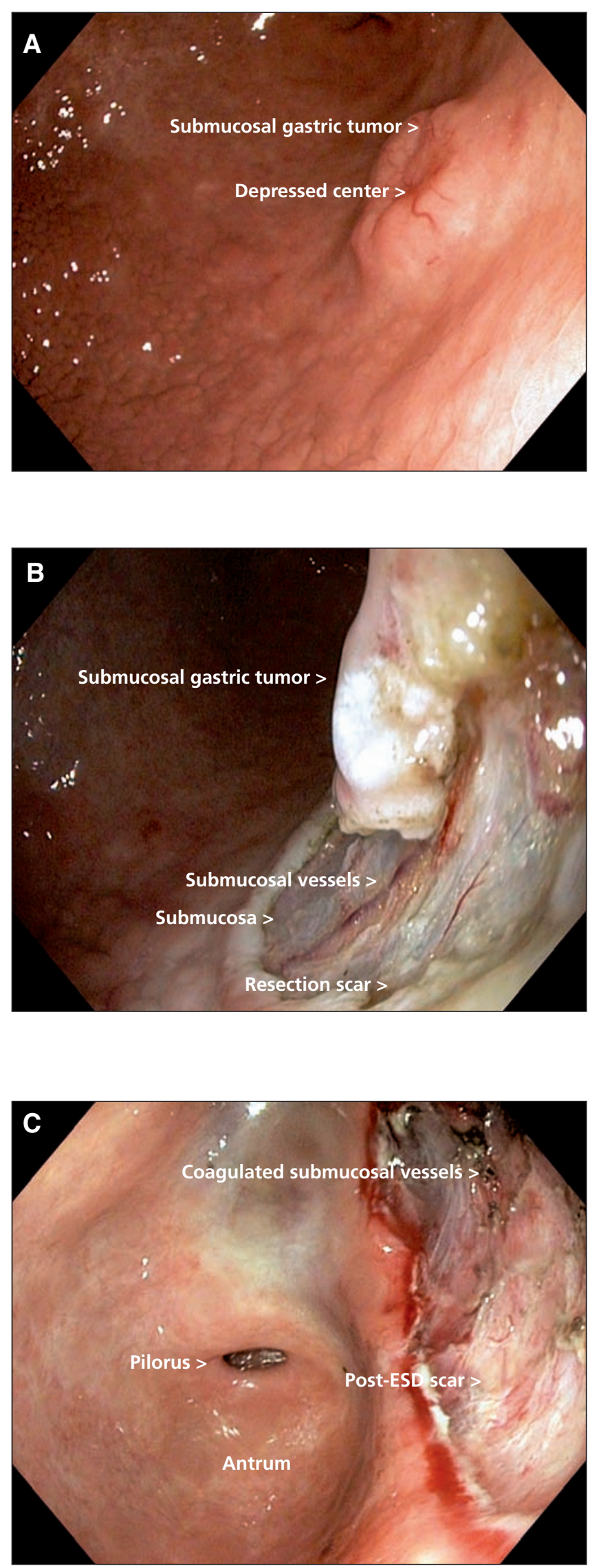
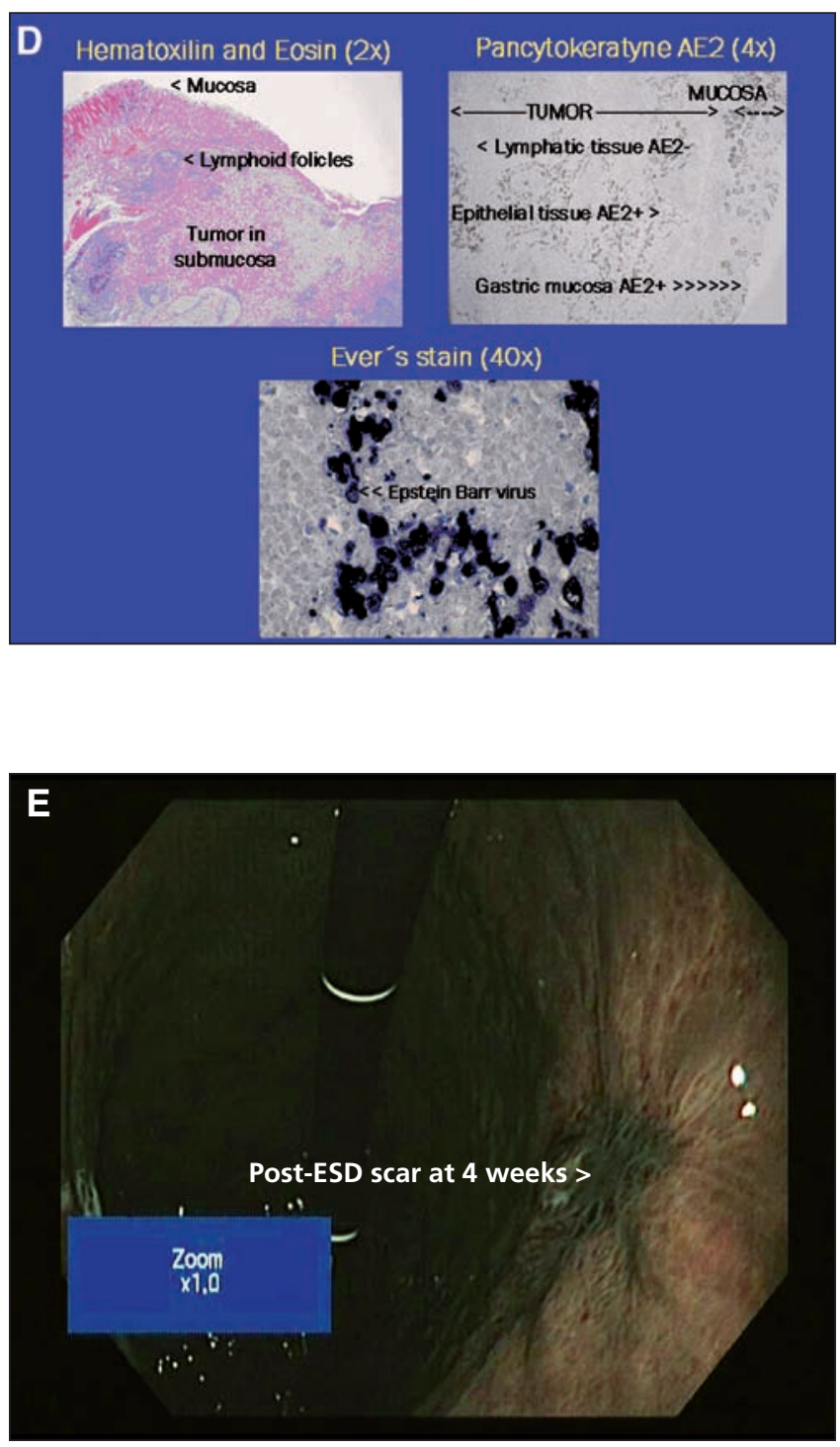

Fig. 3. A. A flat, non-ulcerated tumor with a depressed center may be identified in the posterior wall of the stomach (union between the antrum and body). B. ESD allowed to excise the lesion from the deep planes of the wall (muscularis propria). This image illustrates a moment during the ESD procedure, and shows a blue-colored submucosa after staining with indigo carmin, and the existing submucosal vessels. C. The final scar after completing ESD, showing no visible signs of bleeding or perforation. D. The pathological exam of the resection specimen showed a gastric tumor located within the submucosa, bluish with hematoxilin and eosin stain (2x), with lymphoid follicules at the same level (image located in the left upper quadrant). An immunohistochemical analysis for cytokeratin AE2 (4x) demonstrated the epithelial origin of this tumor (tumor cells were positive for cytokeratin AE2: brown colored after staining). The epithelium of the gastric mucosa served as an internal control for positivity on immunohistochemistry (righ upper quadrant image). These findings, in conjunction with positive in situ hybridization results (Evers stain at 40x) for Epstein-Barr virus (EBER-1), permitted to establish the definitive diagnosis of gastric carcinoma, lymphoepithelioma type (inferior quadrant of the image). E. Aspect of the resection scar at 4 weeks post-ESD showing complete resolution and scarring (image obtained with an Olympus high-resolution gastroscope, $\mathrm{Na}$ rrow Band Imaging/NBI and magnification). 
was proposed with diagnostic and potentially therapeutic intent. The lesion was identified (high-resolution endoscope, magnification, indigo carmin, and Narrow Band Imaging/NBI), its borders were marked with argon plasma, and the tumor was elevated. Three 2-3-mm incisions were made with the needle knife (at 2, 11 and 6 hours). A circumferential incision of the margin of the lesion was made (IT knife), starting from the anal margin and continuing with the oral marging (Fig. 3B). At this point, after placing the transparent EMR hood, we proceeded to elevate the center of the lesion, making the submucosa visible (blue colored by the indigo carmin stain), and finally the deepest part of the lesion was dissected, leaving the muscular/deep submucosa layer exposed after ESD. Vessels identified during ESD were coagulated (Table I). Following the above-described maneuvers, the entire lesion could be resected in a single fragment, leaving a large scar (Fig. 3C). ESD completion took 210 minutes. The resected specimen measured $35 \mathrm{~mm}$ in the macroscopic exam. Pathology and immunohistochemistry demonstrated the presence of a 12 × $25-\mathrm{mm}$ submucosal tumor, with pathological findings being diagnostic of gastric carcinoma (lymphoepithelioma type) that was ultimately confirmed by in situ hybridization techniques for Epstein-Barr virus (Fig. 3D). The patient was fasted for 72 hours after ESD, and then oral intake was reintroduced. The patient was discharged from hospital 7 days after the procedure with omeprazole $20 \mathrm{mg} / 12$ hours orally. Endoscopic controls at 4 and 6 weeks showed a complete healing of the ulcer created by ESD resection (Fig. 3E). The patient experienced no complication (abdominal pain, fever, melena, vomiting, perforation) during ESD or in the post-ESD period. No blood transfusion was required.

\section{DISCUSSION}

EMR is a diagnostic and therapeutic technique with multiple applications in clinical practice (1-8). Learning to perform EMR is relatively easy, and for this reason it has become widely available in recent years $(2,17)$. In contrast, the ESD technique is more complicated and difficult to learn, and to date has only been implemented in Asiatic countries (due to the need to endoscopically diagnose and treat a high number of superficial gastrointestinal tumors occurring in those countries) (8-16,18-20). The major advantage of this type of therapy versus EMR is that it may allow resecting lesions $>1.5 \mathrm{~cm}$ in size in a single fragment, which may facilitate sample orientation and therefore a more complete pathological exam (2).

Technical difficulty, the extended learning curve of ESD, and the reduced number of superficial lesions diagnosed in Western countries are responsible for the limited availability of ESD. Moreover, the absence of experts in this technique in countries like Spain has limited the access to and learning of ESD.

In this sense, we would like to highlight that the ESD of a stomach tumor reported in this study represents the first description/publication in our country. This fact reflects the null presence of ESD in our country, and is in contrast with the extended experience in Asiatic countries (8-20). It would be desirable to have at least one training program on ESD in our country to provide initial skills for ESD performance. The training program proposed in this study, although not the only way to learn ESD in our environment, has clearly shown that by adhering to its 4 steps: 1) review of literature and acquisition of theoretical concepts of ESD; 2) training in an ex-vivo animal model; 3) training in an invivo animal model; and 4) ESD of a gastric tumor in a patient- one may learn to perform ESD in a safe and effective manner. In our opinion, one of the strengths of the present study is that a method for learning ESD has been described, and this training method may be reproduced by other endoscopists. The training method proposed in this study has permitted to train 4 therapeutic endoscopists with no experience on ESD, allowing them to achieve an initial experience in performing this difficult technique. This point is of major importance, as this training model may allow training more than one future "expert" on ESD at the same time. In our opinion, the creation of working groups for training on this difficult technique (experiments with more than one endoscopist performing different parts of the ESD) may allow to obtain a more productive learning experience when compared to learning alone. However, although the model evaluated simulates the ESD procedure and allows to acquire at a low cost (at least the ex-vivo model for training, as the step 3 training on a live model is more expensive and is limited to courses like the one described in the methods section, and to the few animal labs available for endoscopic experiments in our country) the basic skills to perform ESD, the reduced number of patients/cases that may benefit from this type of therapy in our environment makes it unlikely that we shall have real experts in this technique (although some specialists may acquire some basic skills on ESD by the present training method). To find a solution for this issue may be complicated, and in our opinion a potential solution for this problem, as done in other countries, may be to refer ESD patients to a tertiary center in an attempt to centralize this relatively infrequent therapy. This type of practice would likely provide a number of patients to tertiary centers that may potentially allow a group of endoscopists with initial skills on ESD (acquired by this training program) to achieve a higher degree of experience $(>25$ ESDs per year), increase knowledge and experience in the field, and become real experts in this complex technique. By having a number of experts on ESD at certain tertiary institutions of the National Health System more complex procedures (esophagus, colon, duodenum...) may be accomplished, which would probably permit to organize training programs on ESD to benefit other gastroenterologists in the country, and ultimately benefit patients, who will be offered another therapeutic option that is not available at present. The cumulative experience at these tertiary referral centers may facilitate the implementation of this interesting and difficult technique in our healthcare system. 
In summary, the results from the present study support that this model may serve as a good instrument to make endoscopists familiar with this high-risk technique that has been recently introduced in Western countries. The initial training of endoscopists on ESD may facilitate a setup of this technique in some referral centers in the country, and patients with an ESD indication may be referred to those institutions. By doing so, a group of selected endoscopists may become (after some time) experts on ESD, treat patients, and facilitate training for future experts.

\section{REFERENCES}

1. Larghi A, Waxman I. State of the art on endoscopic mucosal resection and endoscopic submucosal dissection.Gastrointest Endosc Clin N Am 2007; 17(3): 441-69.

2. Ono A, Fujii T. Mucosectomía endoscópica del tracto digestivo. GH Continuada 2006; 5(5): 228-33.

3. Hosokawa K, Yoshida S. Recent advances in endoscopic mucosal resection for early gastric cancer. Jpn J Cancer Chemother 1998; 25: 476-83.

4. Soetikno RM, Gotoda T, Nakanishi Y, Soehendra N. Endoscopic mucosal resection. Gastrointest Endosc 2003; 57: 567-79.

5. Ono H, Kondo H, Gotoda T, Shirao K, Yamaguchi H, Saito D, et al. Endoscopic mucosal resection for treatment of early gastric cancer. Gut 2001; 48: 225-9.

6. Ahmad NA, Kochman ML, Long WB, Furth EE, Ginsberg GG. Efficacy, safety, and clinical outcomes of endoscopic mucosal resection: a study of 101 cases. Gastrointest Endosc 2002; 55: 390-6.

7. Varas MJ, Miquel JM, Abad R, Espinós JC, Cañas MA, Fabra R, et al. Interventionist endoscopic ultrasonography. A retrospective analysis of 60 procedures. Rev Esp Enferm Dig 2007; 99(3): 138-44.

8. Watanabe K, Ogata S, Kawazoe S, Watanabe K, Koyama T, Kajiwara T, et al. Clinical outcomes of EMR for gastric tumors: historical pilot evaluation between endoscopic submucosal dissection and conventional mucosal resection. Gastrointest Endosc 2006; 63(6): 77682.

9. Oka S, Tanaka S, Kaneko I, Mouri R, Hirata M, Kawamura T, et al.
Advantage of endoscopic submucosal dissection compared with EMR for early gastric cancer. Gastrointest Endosc 2006; 64(6): 877 83.

10. Saito Y, Uraoka T, Matsuda T, Emura F, Ikehara H, Mashimo Y, et al. Endoscopic treatment of large superficial colorectal tumors: a case series of 200 endoscopic submucosal dissections (with video). Gastrointest Endosc 2007; 66(5): 966-73.

11. Ohkuwa M, Hosokawa K, Boku N, Ohtu A, Tajiri H, Yoshida S. New endoscopic treatment for intramucosal gastric tumors using an insulated-tip diathermic knife. Endoscopy 2001; 33: 221-6.

12. Yamamoto H, Sekine Y, Higashizawa T, Kihira K, Kaneko Y, Hosoya Y, et al. Successful en-bloc resection of a large superficial gastric cancer by using sodium hyaluronate and electrocautery incision forceps. Gastrointest Endosc 2001; 54: 629-32.

13. Yamamoto H. Endoscopic submucosal dissection of early cancers and large flat adenomas. Clin Gastroenterol Hepatol 2005; 3(7 Supl. 1): S74-6.

14. Kodashima S, Fujishiro M, Yahagi N, Kakushima N, Omata M. Endoscopic submucosal dissection using flex knife. J Clin Gastroenterol 2006; 40: 378-84.

15. Sano Y, Machida H, Fu KI, et al. Endoscopic mucosal resection and submucosal dissection method for large colorectal tumors. Dig Endosc 2004; 16(Supl.): S88-91.

16. Saito Y, Takisawa H, Suzuki H, Takizawa K, Yokoi C, Nonaka S, et al. Endoscopic submucosal dissection of recurrent or residual superficial esophageal cancer after chemoradiotherapy. Gastrointest Endosc 2008; 67(2): 355-9.

17. Seewald S, Akaraviputh T, Seitz U, Brand B, Groth S, Mendoza G, et al. Circumferential EMR and complete removal of Barrett's epithelium: a new approach to management of Barrett's esophagus containing high-grade intraepithelial neoplasia and intramucosal carcinoma. Gastrointest Endosc 2003; 57: 854-9.

18. Goto O, Fujishiro M, Kodashima S, Kakushima N, Ono S, Yahagi N, et al. Feasibility of electrocautery snaring as the final step of endoscopic submucosal dissection for stomach epithelial neoplasms. Dig Liver Dis 2009; 41(1): 26-3.

19. Ono H, Hasuike N, Inui T, Takizawa K, Ikehara H, Yamaguchi Y, et al. Usefulness of a novel electrosurgical knife, the insulation-tipped diathermic knife-2, for endoscopic submucosal dissection of early gastric cancer. Gastric Cancer 2008; 11(1): 47-52.

20. Takizawa K, Oda I, Gotoda T, Yokoi C, Matsuda T, Saito Y, et al. Routine coagulation of visible vessels may prevent delayed bleeding after endoscopic submucosal dissection--an analysis of risk factors. Endoscopy 2008; 40(3): 179-83. 